\title{
Timing their moves, healthcare bodies scrub up for a dust-up
}

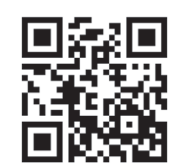

Private healthcare organisations across the country are strategising on whether or when to take on the government, which has promulgated a law that effectively allows the Director-General of Health to tell their members where they can ply their trade or set up facilities and equipment.

At least three of the top doctor bodies have banded together to say that the long-dormant Certificate of Need (CoN) provisions in the National Health Act (NHA), suddenly promulgated by President Jacob Zuma this April, are unconstitutional and will create an administrative nightmare, ultimately undermining incentivised public/ private partnerships.

While eager to help government achieve its aim of redistributing health services to match where the biggest burdens of disease are, they are dead set against having to apply for a certificate before they can legally practise in a geographical location of their choice - or continue doing so. The strategy and timing debate centres on whether to make a legal challenge to the provisions before the regulations, to be drawn up by 1 April 2016, are finalised (based on wide-ranging input from across the health professions), or afterwards. This 2016 date is also the deadline by which all healthcare providers must apply for a CoN. It may well be put back if flustered state lawyers, currently under instruction from a beleaguered national Department of Health $(\mathrm{NDoH})$ to do so, can find the legal wherewithal.

Meanwhile healthcare bodies are attending a flurry of NDoH 'stakeholder consultation' workshops aimed at penning regulations to mitigate the sweeping new legal provisions - while consulting lawyers to protect their rights. Failure to comply with the new law is punishable by a fine, 5 years' imprisonment, or both. The three doctor bodies, the South African Medical Association (SAMA), the South African Dental Association (SADA), and the SA Private Practitioners Forum (SAPPF) (specialists), agree with the noble intentions of the law, but see it as a blunt and coercive instrument that will have grave unintended consequences.

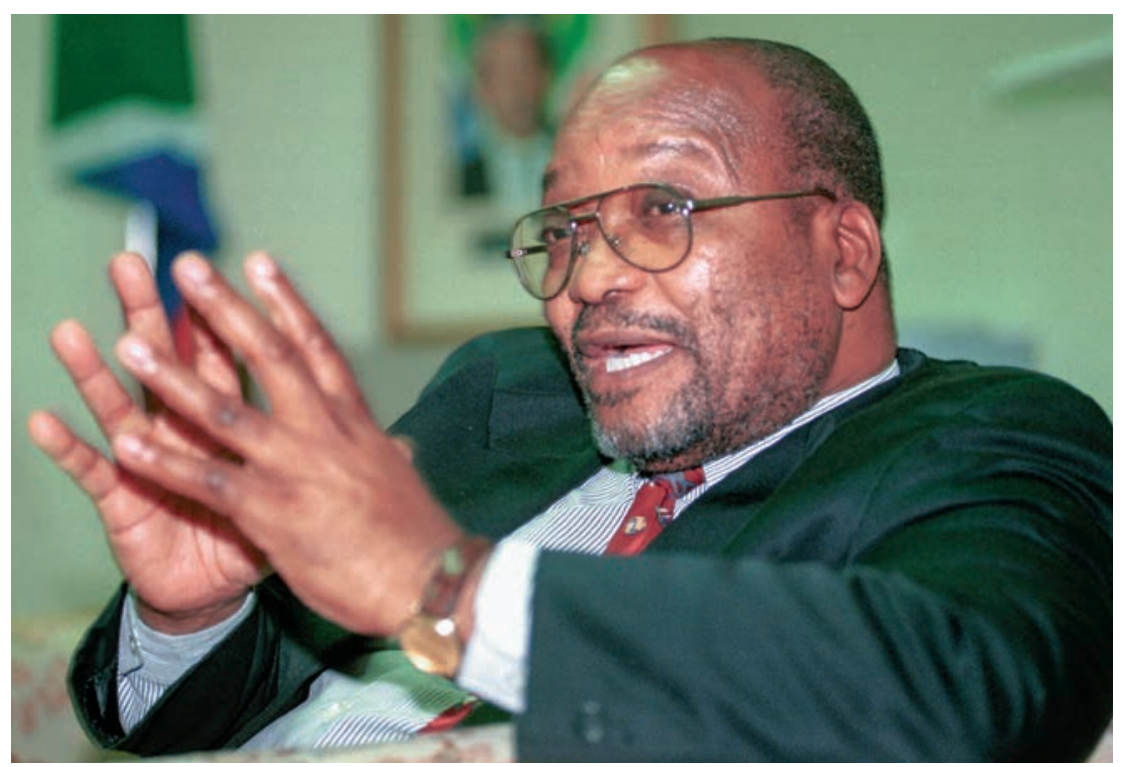

President Jacob Zuma.

\section{What the law says}

All existing healthcare services and establishments - and those intending to practise or establish themselves before 1 April 2016 must apply for a $\mathrm{CoN}$ by that date, with National Health Director-General, Malebona Precious Matsoso, empowered to grant or deny it. While Matsoso and Minister of Health Dr Aaron Motsoaledi have protested loudly and at length that the law will not be used 'arbitrarily or punitively' - Motsoaledi promising that healthcare professionals in existing practices will not be forced to move - the provisions are fairly explicit.

A CoN will be required for anyone: $(i)$ establishing, constructing, modifying or acquiring a health establishment or agency; (ii) increasing the number of beds in, or acquiring prescribed health technology at, a health establishment or health agency; and (iii) providing 'prescribed' health services or continuing to operate a health establishment or health agency after the expiration of 24 months from the date on which the relevant addition to the Act took effect (1 April 2014). The Act requires the Director-General of Health to apply her/his mind to several requirements before issuing a certificate. These include consistency of health services, development in terms of planning, equitable distribution and rationalisation of services and resources (including existing public and private facilities in an area), and correcting racial, gender, economic and geographical imbalances, taking into account the demographic and epidemiological characteristics of the population to be served, plus furthering the Employment Equity Act within emerging small, medium and micro-enterprises.

The contentious provisions were drafted in 2003 by Dr Kamy Chetty and the State Attorney's Office during Chetty's tenure as Deputy Director-General of Service Delivery in the NDoH. This was at a time when nongovernmental bodies and the government were virtually at war over HIV/AIDS, and the quality of law drafting by the State Attorney's office was coming under question. The draft provisions were put on ice when a storm of protest erupted, with SAMA threatening to take the government to the Constitutional Court to counter the threat to the movement and trade of its 17000 doctor members. It took nearly a month before dozens of private healthcare professional bodies, hospital associations and non-governmental organisations woke up to the recent 'fait accompli', many of them having to scamper to revive institutional memory before they could take a position.

Wide consultation - but will it make a difference? At the time of writing (4 July), Matsoso had held talks with over two dozen top 
healthcare professional bodies, with several worried independent practitioners putting their practices on hold to travel to Pretoria to get the lowdown for themselves. Matsoso openly admits that many professional bodies

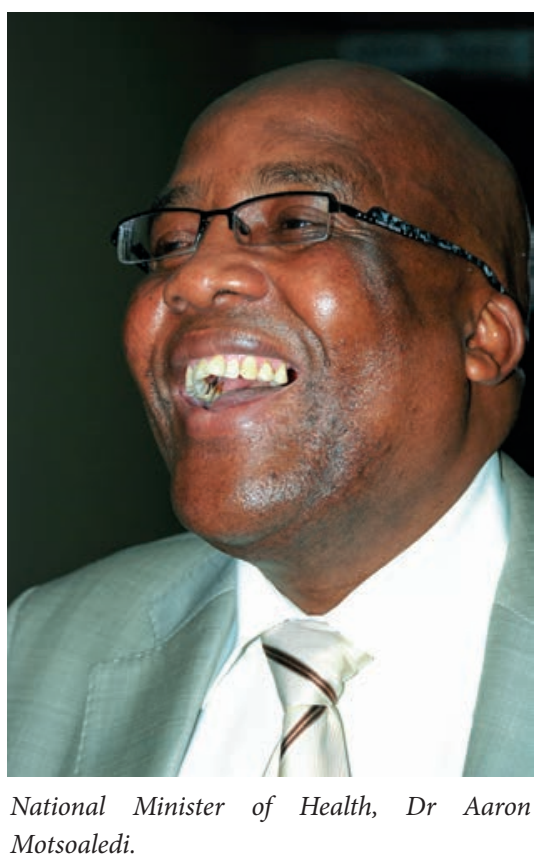

are arriving with lawyers in tow. Initial examination of the legal provisions by their detractors reveals that they not only severely limit the rights of healthcare providers, but arguably those of patients accessing care and medical information (if any existing practices have to close). They could render existing medical businesses worthless (although Matsoso says there is provision for ensuring 'financial viability') and, perhaps most insurmountable, create a mountain of red tape with a huge and expensive bureaucracy (more than 70000 healthcare establishments have to be registered by 1 April 2016). Practical administrative issues such as selling a practice or taking on partners (with debate on grandfathering clauses and whether the CoN applies to individuals as well as practices), and the clashing of the CoN with at least six other existing laws, including the Competition Act, Consumer Protection Act, Promotion of Access to Information Act, Promotion of Equality and Prevention of Unfair Discrimination Act, Health Professions Act and Protection of Personal Information Act, look set to pose a legal nightmare. Matsoso has, by briefing state lawyers, admitted that the 1 April
2016 deadline is unrealistic. A consultative committee consisting of five members representing all healthcare professional bodies is being set up by her department to inform regulation writing, while all who attended the briefings have been given 30 days to make written submissions.

\section{What the doctors say}

Dr Mzukisi Grootboom, SAMA chairperson, says that in spite of the wellmeaning intensive consultation, the primary legislation is a fait accompli. Of the primary law he says: 'As South Africans we all know what needs to be done, but we're not hearing each other. It's like a dialogue of the deaf. We implement things that pit us against each other. It's a reflection of the kind and quality of legal professional advice they're getting.' SAMA would do all it could to ameliorate the situation, provided Motsoaledi was genuine in ensuring co-operation and avoiding disruption of health services. Grootboom adds: 'The very intention of improving access may deny it, as doctors suddenly find themselves without licences and unable to practise. Also, the clock is ticking to put all this into practice. We cannot understand why

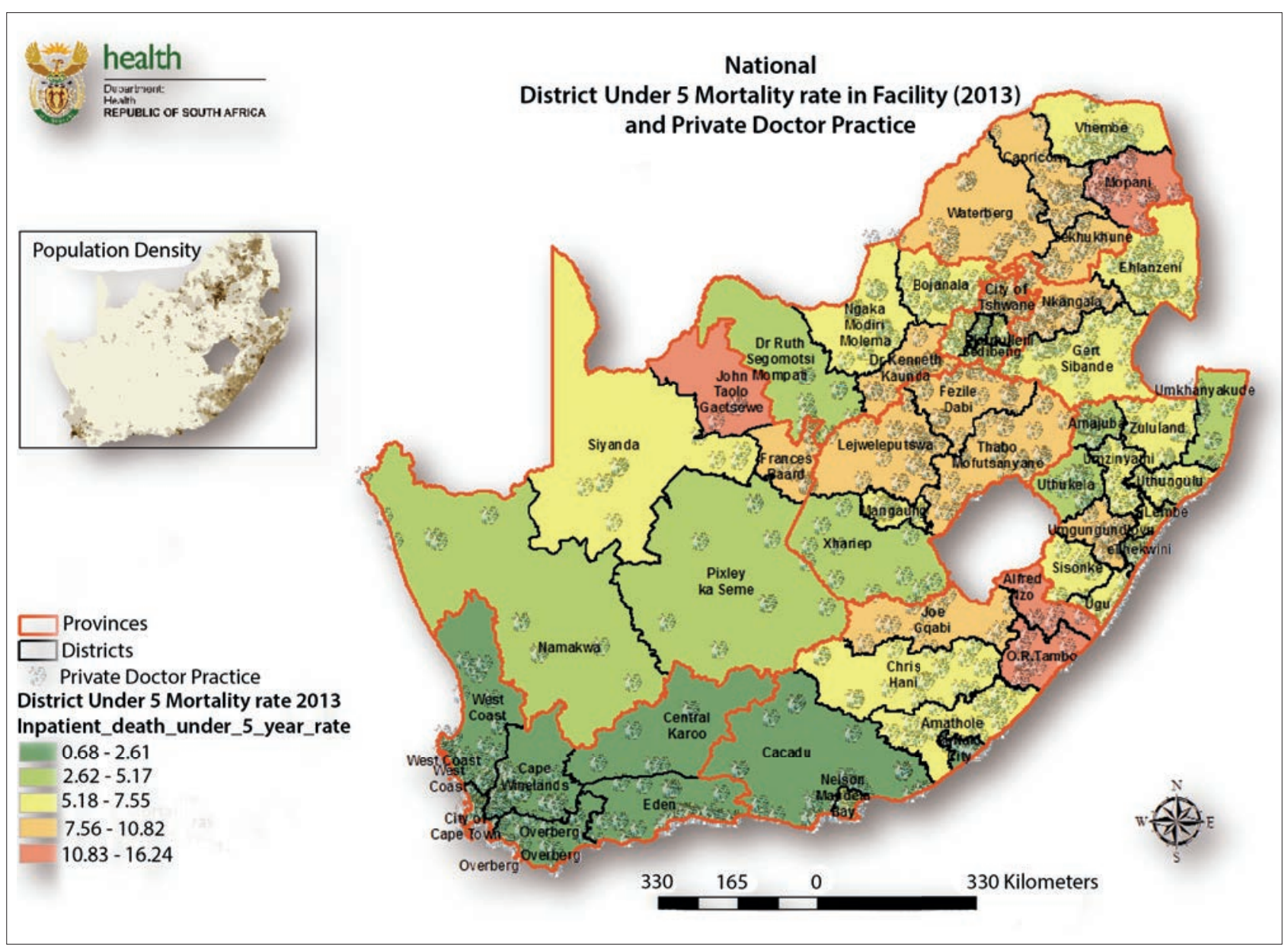

Fig. 1. National district under-5 inpatient mortality rate and distribution of private doctor practices, 2013. (Source: National Department of Health.) 


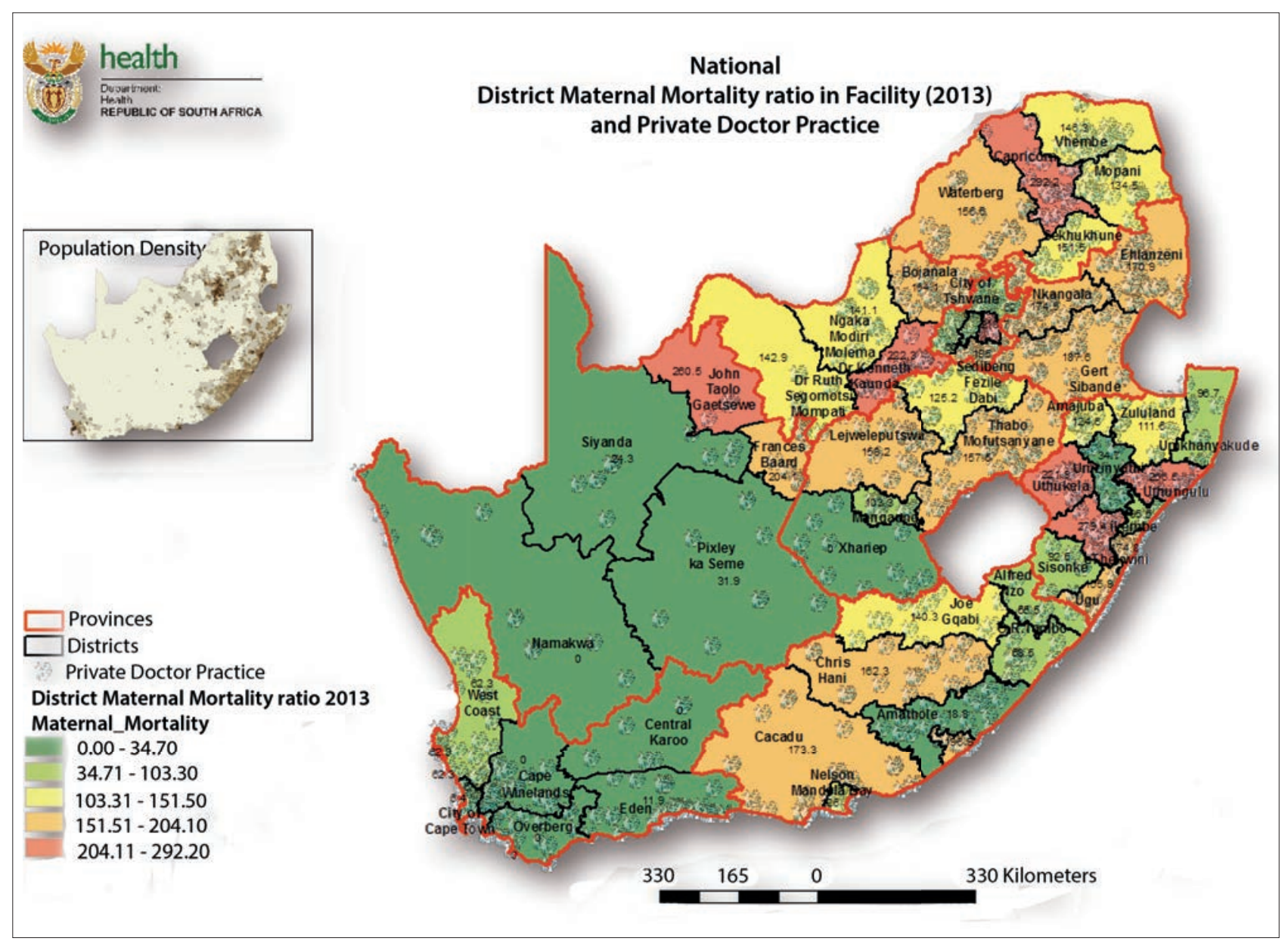

Fig. 2. National district maternal mortality ratio and distribution of private doctor practices, 2013. (Source: National Department of Health.)

government would promulgate a section of the law which they know is unconstitutional.' He refused to rule out Constitutional Court action at a later stage.

Dr Chris Archer, CEO of the SAPPF, the largest body of specialists in the country, says that the NDoH's central problem is how to deal with the mismatch between the burden of disease distribution and the distribution of health services (as illustrated in Figs 1 and 2). 'The private sector cannot be expected to supply services in areas of low or non-existent economic activity and the CoN will not solve that problem. Innovative public/private partnerships that do not depend on the development of fixed capital-intensive infrastructure offer a possible solution - without the need for a CoN.' Archer said that even if the Director-General was magnanimous in her application of the law, 'they still have the power', asking, 'what happens when the DG or the Minister of Health change?'. Such a system would also create fertile ground for bribery and corruption and act as a further driver to healthcare workers leaving an already skeletally staffed system. He asked who would invest in infrastructure in their practices in a 'Park Lane-type clinic' if they were unable to 'on-sell' the practice upon retirement. No amount of 'tinkering with regulations' would succeed in resolving the most contentious issues. The late offer to consult was 'too little, too late - we genuinely want to assist, but this authoritarian use of legislative power approach will only cause resentment and resistance, he added.

Maretha Smit, CEO of SADA, said she was 'constantly amazed at the decisions taken without an understanding of the risks attached and a comprehensive analysis of the downstream impact and potential of where things could go wrong. She warned that this could result in a dramatic reduction in people wanting to enter the healthcare professions, with dire national implications given current critical staff shortages. Alienating the professions would simply mean that government 'won't be able to reach their targets'. The over-riding focus for practitioners had become 'how do I survive?' instead of 'how do I care?.' 'If we take the "how do I survive" out of the equation, you'll get a lot more people saying, "how do I care?", she added. Like many other healthcare professional bodies, both SADA and the SPPF are contemplating testing the provisions in the Constitutional Court.

\section{The DG dons the velvet glove}

Matsoso, a former World Health Organization Director of Health Innovation and Intellectual property (Geneva, January 2005 June 2010), stressed: 'This is not a command and rule, enforcement approach. I want to fix this via consultation on the regulation, reading the primary provisions with others in the NHA, and interacting in a manner that is anything but punitive. We don't want the kind of outcomes doctors fear. There's nothing in there that says, "take people from towns and put them in townships" - unless you want to attach redistributive policies to that - but the Act doesn't say so. Even if it's implied, it can't be done contrary to the supreme law of the land, the Constitution.' She said all ongoing stakeholder consultations include graphic illustration of demographic and epidemiological profiles of different provinces and districts, overlaid with the distribution of professional groupings, from data collected over the years. Motsoaledi's initial impromptu response to Izindaba 
was: 'I don't understand all the objections I mean [Netcare] Park Lane Clinic [in Parktown, Johannesburg] has more gynaes than Limpopo and Mpumalanga provinces put together! It will be difficult to force them to move - but should we allow more gynaes to move into that small space called Park Lane? I don't think so!'

Motsoso promised: 'I'm going to translate the primary law through secondary regulation,' adding that reading the $\mathrm{CoN}$ provisions in isolation from the rest of the NHA 'leads to misinterpretation'. She said 'some brilliant ideas' had come from the biggest objectors, including establishing objective criteria for 'grandfather clauses' (to protect established practices) and using a weighting system for different disease conditions, with dentists offering to develop a 'toolbox' of packaged services, while GPs suggested she use some of their existing independent practitioner association guidelines. 'It's very exciting - if we do this right, we can come up with a do-able model'; she said. The NDoH would use the registration data from the Health Professions Council of South Africa and other statutory councils to facilitate the granting of CoNs. A major advantage of the $\mathrm{CoN}$ would be its use as a tool to ensure that norms and standards set by the Office for Healthcare Standards Compliance (OHSC) regarding public sector equipment and staff distribution were adhered to. The OHSC had completed setting norms and standards for all public sector primary healthcare facilities, but was still busy working out staff distribution norms for tertiary health facilities, with a 'major rationalisation process' due. (It has yet to begin on the private sector - yet another administrative hurdle.) Matsoso said the CoN would also help the $\mathrm{NDoH}$ remove a long-standing thorn in its side by giving Pretoria the power to direct how provinces allocate their health budgets instead of being beholden to maverick, often hugely ineffective, provincial political allocation.

\section{Silver lining for the} private sector?

One source said that the NDoH was considering reallocating part of the $\mathrm{R} 9$ billion annual health infrastructure budget (given the healthcare staffing crisis) and using it 'more productively' to fund public/private partnerships, thereby increasing access to healthcare. Responding to the lack of initial consultation, Matsoso replied: 'I cannot think of a single government department that says to stakeholders, "before we even start, can we talk about what the issues are?". She described portions of the NHA as 'bizarre and badly written', saying it required constant fine-tuning.

\section{Chris Bateman}

chrisb@hmpg.co.za

S Afr Med J 2014;104(8):530-533.

DOI:10.7196/SAMJ.8653 